\title{
Ecologia, educação e utopia: Wilson Rocha e a literatura infanto-juvenil na década de 80.
}

\section{Larissa Rosevics}

Mestranda em Sociologia na UFPR. Especialista em Sociologia Política pela UFPR e em Literatura Brasileira e História Nacional pela UTFPR.

Resumo: O presente artigo procura analisar as dimensões utópicas existentes nos livros O Filho das Estrelas (1989) e Os passageiros do futuro (1987) de Wilson Rocha e suas relações com a discussão global sobre ecologia na década de 1980. Entendendo ser a educação o melhor meio para desenvolver nas crianças e jovens a consciência ecológica, procurou-se demonstrar como, através da literatura infanto-juvenil, o autor transmite uma preocupação ambiental local e global. Apesar dos livros de Wilson Rocha não serem utopias nem distopías, ele utiliza elementos de ambas para desenvolver suas narrativas e construir uma conscientização ambiental.

Palavras chaves: Wilson Rocha, ecologia, educação, utopia, distopía, literatura infanto-juvenil.

\section{INTRODUÇÃO}

As motivações que levaram a elaboração do artigo surgiram das discussões sobre literatura e utopia apresentadas pelo professor Gilson Leandro Queluz na especialização em literatura brasileira e história social da Universidade Tecnológica Federal do Paraná. Seria a ecologia, uma das maiores utopias já propostas aos homens? As últimas décadas do século XX foram frutíferas na construção de uma consciência ecológica, muito graças às discussões mundiais sobre o tema e a educação ambiental desenvolvida nos diversos ramos da sociedade. No entanto, muitas barreiras ainda devem ser derrubadas para que as ameaças pelas quais as espécies vegetais e animais do planeta sofrem, como o desmatamento, o aquecimento global e a destruição da biodiversidade, possam desaparecer.

Dentre os diversos livros publicados por Wilson Rocha destinados aos públicos infantil e infanto-juvenil, praticamente todos abordam de uma maneira ou de outra as questões ambientais. Seus personagens e leitores, ao longo dos textos, descobrem as conseqüências da destruição do meio ambiente, assim como são motivados a lutarem pela preservação do mesmo.

\section{2- O AUTOR WILSON ROCHA}

Nascido no Rio de Janeiro em 1931, Wilson Rocha é formado em Direito e trabalha como autor, diretor e roteirista de teatro, cinema e televisão, contratado pela Rede Globo desde a década de 60. Na televisão, escreveu episódios do Sítio do Picapau Amarelo e envolveu-se em projetos como as novelas Seu Quequé e Olhai os lírios do campo, os especiais infantis Pirlimpimpim e Plunct-plact-zuum, além de documentários.

Portanto, quando chegou ao mundo dos livros infantis, o autor já tinha 
experiência com o fantástico e fantasioso mundo das crianças. Seus primeiros livros para esse público foram Sorte é sorte, $A$ história de Leo, O piano pirado, O que vou ser quando crescer. Pela editora Ediouro, lançou os livros Até quando caras pintadas? e Código da Ushuaia e pela editora Quinteto, O perigo me procura. Mas foi em 1987 que Wilson Rocha lançou aquele que viria a ser o seu livro de maior repercussão, Os passageiros do futuro, que passou a integrar a tradicional Série Vagalume da editora Ática, sendo indicado para alunos de 7ạ e 8a séries. Ainda pela Série Vagalume, o autor lançou em 1993 Um gnomo na minha horta e em 1995 O Fabricante de Terremotos.

Dois anos mais tarde de Os passageiros do futuro, Wilson Rocha publicou pela editora Moderna o livro $O$ filho das estrelas e Os robôs dos botões lônicos na coleção Veredas. Na coleção Girassol da mesma editora, saiu o livro $O$ avião do rei.

Em suas obras infanto-juvenis, é comum encontrar a preocupação ecológica, com o meio ambiente e com a qualidade de vida dos seres humanos. Assuntos como destruição das matas, da camada de ozônio e o relacionamento dos seres humanos com a natureza são recorrentes. Em Um gnomo na minha horta os personagens principais são um menino chamado João Filipe e seu amigo o gnomo Casca de Bétula. Messer, o garoto inglês protagonista de $O$ perigo me procura vive uma aventura na Amazônia brasileira.

Segundo Raymond Trousson (1995, p.39-41), o autor utopista, aquele que produz uma literatura com conteúdo utópico, está intimamente ligado com seu tempo histórico e profundamente decepcionado com ele, por isso opta por construir através da sua imaginação um mundo conforme o seu desejo, como deveria ser, seja através de uma retificação da realidade ou de um mundo irreal.

[...] el utopista se siente incómodo en la sociedad de su tiempo, cuyas taras advierte y condena [...] opta por borrar la realidad para reconstruirla en el pensamiento, crear un mundo conforme a sus deseos [...] la utopía es por esencia histórica, ya que está determinada por sus relaciones con la realidad.

Ao longo do século XX, guerras, bombas, miséria e destruição levaram, por um lado, a um desencantamento do indivíduo com a humanidade, mas por outro a um resgate cada vez maior por parte da comunidade internacional da necessidade de condições mínimas para a preservação do planeta e da sobrevivência da espécie humana.

Wilson Rocha demonstra, ao longo de sua obra, ter traços de um utopista ao revelar certa decepção com o gênero humano graças à destruição da natureza, ressaltando a importância do meio ambiente para a vida. O escritor não é um ser isolado de seu tempo histórico e a preocupação explicitada por Rocha é um pouco a de toda uma geração que nas últimas décadas vêm discutindo e repensando a relação do homem com a natureza.

Essas reflexões resultaram, ao longo dos anos, em convenções e tratados internacionais de preservação ambiental e de políticas de desenvolvimento sustentavel para os países. 


\section{RESGATE HISTÓRICO DAS QUESTÕES ECOLÓGICAS}

Após as duas Guerras Mundiais e principalmente o evento da bomba atômica, preocupações com a influência do homem sobre o ciclo natural do meio ambiente tornaram-se parte da agenda de discussão dos diversos países do globo, proporcionando inclusive o estabelecimento da Ecologia como uma ciência. Essencialmente internacionais, as questões ambientais ultrapassam as fronteiras políticas dos Estados, graças aos impactos que às ações a elas ligadas podem proporcionar.

No ano de 1968, aconteceu em Paris o primeiro encontro internacional para estabelecer as diretrizes para uma discussão sobre meio ambiente. A Conferência da Biosfera procurou regulamentar aspectos científicos da biosfera, definida como "[...] aquela parte do mundo na qual a vida pode existir, incluindo-se portanto certas partes da litosfera, da hidrosfera e da atmosfera" (MACCORMICK, 1992, p.98). A Conferência das Nações Unidas sobre o Meio Ambiente Humano, realizada no ano de 1972, é considerada o marco fundamental no crescimento do ambientalismo internacional. Nela foram discutidos os problemas sociais, econômicos e políticos do meio ambiente global, criando no seio das Nações Unidas bases para uma definição mais abrangente dos problemas do meio ambiente humano, fundamentais para convergir à atenção de governos e da opinião pública para a importância do problema.

A natureza e as questões ambientais fazem parte do imaginário brasileiro, desde a chegada dos portugueses no século XVI, seja pela exaltação, pela abundância ou pela exploração. Conhecido pelas suas belezas naturais, ao Brasil são associados diversos mitos como o Paraíso Perdido das passagens bíblicas, como retrata Sergio Buarque de Holanda em Visão do Paraíso. A literatura romântica do século XIX trouxe muito desse imaginário com a exaltação da natureza e do indígena.

Durante a década de 1980, o desmantelamento da União Soviética e a aproximação do fim da Guerra Fria deram um novo fôlego para a discussão sobre o meio ambiente global, a necessidade de uma conscientização da população e de normatização mais efetiva sobre a questão. No Brasil, o Meio Ambiente e as questões relativas a ele surgiram juridicamente a partir da lei 6.938/81, que instituiu a Política Nacional de Meio Ambiente e criou o Sistema Nacional do Meio Ambiente. A Constituição de 1988 também não foi omissa a questão ambiental, tratando deste no Capítulo VI art. 225. Portanto, tanto para o Brasil como para o mundo, a década de 80 foi um importante período de revitalização da discussão sobre a problemática ambiental, sua regulamentação e sua divulgação junto as diversas sociedades do globo.

Esse contexto levou as Nações Unidas a fazer uma terceira grande conferência internacional sobre o assunto, Conferência das Nações Unidas para o Meio Ambiente e o Desenvolvimento, também conhecida como ECO-92, que aconteceu no Rio de Janeiro em 1992. Através dela foi aprovada a Convenção da Biodiversidade e a Agenda 21, que 
procuraram tratar de questões como desenvolvimento sustentável, camada de ozônio, qualidade de vida e conscientização da população, dentre outros.

Um dos aspectos mais discutidos na ECO 92 foi a importância da educação no processo de conscientização das populações quanto as questões ligadas a natureza. $O$ encontro das Nações Unidas apenas formalizou uma discussão que esteve em pauta entre os pensadores dos anos 80, e que teve reflexos no campo literário, como pode ser observado nas obras de Wilson Rocha. Como destaca Mauricio André Ribeiro (1998, p.32):

\begin{abstract}
Transformar valores culturais e imprimir-lhes feição ecológica implica ações difusas, descentralizadas e de longo prazo; demanda transformações na educação formal e informal, na tecnologia, na filosofia e nas mentalidades, na forma de conceber e utilizar o mundo e os recursos do ambiente, na mitologia e nas tradições espirituais, em direção à perspectiva pós-materialista.
\end{abstract}

Dentro da literatura infanto-juvenil produzida por Wilson Rocha, Os passageiros do futuro e $O$ Filho das Estrelas são os livros que expressam mais claramente a sua preocupação ambiental. No primeiro livro, através da história de quatro adolescentes, o autor procura relatar um futuro em que já não existe mais natureza, e a reação desses mesmos adolescentes ao terem contato pela primeira vez com o ambiente natural, em uma viagens ao passado. Já no segundo, o personagem central é educado por alienígenas para ser o protetor do planeta terra contra a destruição causada pelo homem. Ambos os livros não são utopias propriamente ditas, mas, o autor se utiliza de dimensões utópicas e por vezes distópicas para poder desenvolver ambos os enredos, na procura da construção de uma concientização ecológica.

\title{
4 DIMENSÕES ÚTOPICAS DE OS PASSAGEIROS DO FUTURO 1
}

A inconseqüência dos atos humanos transformou o mundo de Os passageiros do futuro, no século XXX, num lugar árido, em que a Amazônia e os oceanos viraram grandes desertos e quase toda a flora e fauna foram destruídas.

\begin{abstract}
Tinham se tornado comuns, em 3000, os desertos como aquele. Mas o de Zônia era, sem dúvida alguma, o maior deles. Uma brutal extensão de terra vazia e árida (mais de três milhões de quilômetros quadrados), que outrora foram a maior massa vegetal e o principal reservatório de oxigênio do planeta. Porem, os grandes desastres ecológicos do século XXIV secaram os rios (ali tinha corrido, no passado, o maior volume de água do mundo), devastaram a floresta e dizimaram a fauna. Uma tragédia que teve uma compensação, apenas razoável, no crescimento cientifico e tecnológico da humanidade. Mas a antiga beleza daquela região morreu para sempre. (ROCHA, 1987, p.9-10)
\end{abstract}

Se, por um lado, o planeta sofrera uma destruição completa do meio ambiente, a ele restaram duas compensações, a primeira foi o desenvolvimento científico e tecnológico, e a outra a conscientização da população quantos as questões ecológicas e a igualdade. Assim como nas sociedades utópicas clássicas, a construída por Rocha 
no ano 3000 é baseada em regras homogeneamente, aceitas e seguidas por todos, e as transgressões são praticamente inexistentes. "Travessuras eram um fato incomum no ano 3000, época em que as crianças e os adultos tinham se tornado seres rigorosamente disciplinados e ajustados às leis." (ROCHA, 1987, p.20)

Quando o adolescente Delon, personagem central da trama, viaja no tempo retornando para o Rio de janeiro de 1987 e se depara com uma favela, sua reação é comparar a sociedade atrasada do século XX com a sua, organizada, homogênea e vantajosa até certo ponto para se viver:

\begin{abstract}
Delon todo o tempo resistia à vontade de fazer perguntas. Mas não podia entender o que estavam dizendo. Pagar para morar? Era uma idéia inadmissível. No século XXX a Instituição praticamente obrigava as pessoas a aceitar boas moradias, que ela própria indicava. Todos podiam até escolher. A distribuição de residências era farta. [...] A aceitação da fatalidade era algo considerado infantil entre os habitantes de seu tempo. No século XXX, a segurança era o requisito principal em todas as atividades humanas. Nenhum tipo de fantasia ou pendor poético faria um homem correr riscos desnecessários, ou mesmo abrir mão de seu conforto. (ROCHA, 1987, p.82)
\end{abstract}

Nos romances utópicos, há em geral a figura de um viajante, de um ser que não pertence àquela realidade, que ira tomar conhecimento da existência dela e em geral, fará a narração. No caso de Os passageiros do futuro, a situação assemelha-se a uma distopía, ou seja, uma antítese da utopia, pois são os adolescentes B-Hor, Plick, Thera e Delon que através de uma "travessura" acabam viajando ao passado e conhecendo um mundo imperfeito socialmente perto do que vivem, mas que ainda contem as belezas naturais que a eles só eram acessíveis através de computadores e museus. A principal crítica a sociedade do século XXX vem de Delon, o líder entre os adolescentes que protagonizam a história, quando procura defender os amigos das acusações de violação das regras que haviam feito: A defesa que Delon fez dos colegas e de si próprio foi excelente. Um verdadeiro
grito de liberdade, há muito tempo não ouvido no mundo (pelo menos no GLS) [...]
Delon falou de um mundo que tinha tudo, especialmente ali no Território Brasílio,
onde moravam, a região mais bem dotada cientificamente na Terra. Um mundo
em que todos tinham desaprendido pedi, reclamar, porque aparentemente as
coisas Ihes vinham facilmente às mãos. Depois das catástrofes ecológicas do ano
2300 , tinham aprendido a lição, e criando estruturas e leis à prova de perturbações
climáticas, de desentendimento entre os povos. Vivia-se agora num planeta
absolutamente seguro e confortável. Mas absolutamente chato! (ROCHA, 1995,
p.25-26)

A primeira vez que Delon vê o mar como ele era antes dos desastres, em sua viajem a 1987, faz com que ele questione o avanço tecnológico do seu tempo frente a perda da natureza. "Ali, em 1987, o mar ainda era tão lindo. De que valiam os avanços da tecnologia e da ciência - o bem-estar do ano 3000 - se ninguém poderia mais ver um mar como aquele? Se ao menos fosse possível fazer alguma coisa...." (ROCHA, 1995, p.64). A verdadeira sociedade utópica, na visão de Wilson Rocha, passa a ser aquela que além do desenvolvimento econômico, tecnológico e do fim da desigualdade social, conseguisse preservar o meio ambiente e viver harmonicamente com ele. Por 
isso sua sociedade do ano 3000 não pode ser considerada utópica, mas os elementos utópicos presentes ao longo do texto produzem sim uma reflexão de como atingir uma condição sustentável para o planeta, ambiental e socialmente.

Uma última dimensão utópica importante presente em $O s$ Passageiros do Futuro é a questão da educação. "La pedagogia ofrecerá el mejor medio de accion directa sobre el material humano a fin de uniformizar las consciencias."(TROUSSON, 1995, p.49). O enredo do livro se desenvolve em torno da violação as regras da escola que os quatro adolescentes freqüentavam, chamada de GLS - Grande Laboratório de Sapiência - e a viagem no tempo, que acontece acidentalmente quando eles estão tentando resolver alguns problemas sem que sejam descobertos.

A utopia aspira, assim, à síntese totalitária da sociedade, á sua harmonia total, produzida pelo homem e, portanto, antropocêntrica e racional. A reprodução do sistema se fará através da educação, pela qual as novas gerações poderão ingressar nesse todo harmônico e nele se inserir sem modifica-lo. (KERN, 1994, p.32)

A GLS é retratada como uma escola ultra-sofisticada, que é comandada por um computador muito avançado de nome Jupter, mas que todos chamavam Grande Bolha, graças a seu formato arredondado. Esse computador seria responsável pelo julgamento tanto dos adolescentes quando eles infringem as regras da escola quanto da sociedade em geral. Ele é o responsável pela educação, através da qual pode inserir em seus alunos as normas que regem a sociedade, um sistema bastante totalitário, apesar de humanista. $O$ inspetor Milas aparece durante a obra como um personagem que personifica a opressão e, a possibilidade de que ele se torne o novo Grão Programador de Grande Bolha, causa certa intranqüilidade entre os adolescentes e seus pais.

É importante ressaltar que, no ano de 1987 o Brasil via a derrocada do regime militar e a ascensão da democracia. De certa maneira, o autor procura representar em sua obra a importância dos valores democráticos para a sociedade brasileira, em especial para os jovens. A personagem Milas, portanto, representa a continuidade de um sistema repressor, como a ditadura e em contrapartida, a personagem Sr. Delon Pai, a outra alternativa para o cargo de Grão Programador, é retratada como sendo flexível, inteligente e cheia de ideais, aquela que traria a GLS novamente uma democracia:

\footnotetext{
- Claro, o senhor poderia se candidatar e eu o apoiaria. Creio que todos aqui fariam o mesmo. Acreditamos que alguém como o senhor é muito melhor que o inspetor Milas para Grão Programador. Se conseguirmos o apoio dos outros pais, também seríamos maioria. Poderíamos levar a idéia a Grande Bolha. Influenciá-la. Convencê-la. Quem sabe já está na hora de ela voltar a aprender uma coisa que antigamente chamavam... Democracia? (ROCHA, 1987, p.91)
}

\section{DIMENSÕES ÚTOPICAS DE O FILHO DAS ESTRELAS ${ }^{2}$}


lugar no mundo. Seu insularismo pode ser representado através da imagem de uma Ilha, como emA Utopia de Thomas More, ou até de cidades perdidas dentro de grandes selvas. Essa dimensão foi explorada por Wison Rocha em $O$ Filho das Estrelas, em que o personagem principal, um menino de dez anos chamado Marcelo encontra uma cidade perdida no meio da mata do Planalto Central brasileiro.

Após perder-se do pai, um arqueólogo a procura de uma cidade perdida, Marcelo a misteriosa cidade, que é descrita com as mesmas características físicas presentes nas cidades utópicas, geometricamente planejadas e racionalmente organizadas. Como afirma Arno Kern (1994, p.33):

Desde a Antiguidade Clássica, o planejamento urbano está associado aos projetos de cidades dos utopistas. No Renascimento, novamente o urbanismo traça planos racionalistas e geométricos, ciosos da ordem e da centralização social: sonha-se utopicamente com uma nova sociedade. A construção arquitetônica da nova cidade soma-se à construção utópica dessa nova sociedade.

A descrição da cidade que Marcelo encontra e posteriormente a apresentação de seus "habitantes", seres alienígenas mais avançados social e intelectualmente, demonstra a relação que se busca nas utopias da organização urbana com a organização social, uma relação muito forte no imaginário dos estudos sobre cidades:

Com a cabeça girando e um aperto esquisito no estômago, Marcelo procurou entender aquela visão, diferente de tudo que conhecia. Lá embaixo havia um vale, liso e descampado. Até onde a vista alcançava, a terra avermelhada não apresentava nenhum sinal de vegetação. Sobre ela, contrastava violentamente com a aridez da paisagem, havia gigantescas construções reluzentes, cujas faces eram imensos triângulos espelhados, que refletiam violentamente o sol.

Onde já vira formas assim? Pirâmides! Sim, pirâmides, porém nada daquelas ruínas do Egito, feitas de blocos de pedras superpostas. Aquelas eram metálicas, como objetos cromados decorativos, exageradamente ampliados. Marcelo contou seis, sete, oito, nove pirâmides alinhadas três a três, formando um grande quadrilátero. Em suas faces lisas, nenhum sinal de portas ou janelas. (ROCHA, 1989, p.17).

A consciência ecológica no livro, parte de uma sociedade diferente daquela do tempo em que se passa a história, assim como em Os passageiros do futuro em que os adolescentes eram humanos, mas de uma era mais avançada, que relatam à diferença de se viver em um mundo sem natureza. No caso de $O$ Filhos das Estrelas, é da experiência do povo alienígena que viu a destruição de um planeta irmão a Terra que vem a preocupação com o mundo e os seres humanos. Mesmo a preocupação com a camada de ozônio que esta presente no final do livro, é algo que os alienígenas procuram ajudar a solucionar.

Na mesma galáxia de Nébula existe um planeta chamado Astéria, praticamente gêmeo da Terra: o mesmo tamanho, os mesmos tipos de clima, a mesma topografia - tudo! Astéria percorreu um ciclo vital idêntico ao da Terra, só que regrediu a seu estado primitivo, devido a incontrolável catástrofes causadas por seus próprios habitantes. Astéria tornou-se um mundo morto e desértico, com um povo decadente, ignorante e miserável, a quem Shandragun procurava ajudar, oferecendo-Ihe condições para que sobrevivesse e voltasse a civilizar-se. (ROCHA, 1989, p.26) 
Novamente, a educação será parte fundamental no processo de conscientização ecológica, através de uma doutrinação do individuo. Marcelo, graças a uma marca de nascença chamada pelos nebulanos de Shofa, é considerado um Filho das Estrelas, um descendente humano de uma casta interplanetária de Salvadores do Universo, e cabe aos alienígenas educa-lo para que ele possa cumpri a sua missão na Terra, de proteger o ecossistema terrestre da depredação do ser humano. Marcelo deixa de ser um simples humano e passa a ser lorula, com ensinamentos avançados e capaz de poder levar a diante sua missão.

Em uma pequena autobiografia do autor ao final do livro, Wilson Rocha procura sintetizar seu pensamento sobre o livro: "O Filho das Estrelas é um novo chamamento às consciências. Através dele, e de outros projetos que pretendo continuar desenvolvendo, espero ajudar, de alguma forma, as pessoas e ao mundo em que vivemos" (ROCHA, 1989, p.48).

\section{CONCLUSÃO}

Como se pode observar, Wilson Rocha não escreveu uma utopia propriamente dita, um livro que abarque todas as características tradicionais dos livros utópicos, tais como: cidades isoladas, com leis que todos obedecem e que uniformizam a sociedade; da organização geométrica e racional das cidades que reflete a organização social; de viajantes que viveram o contraste com aquela realidade; das relações de trabalho bem definidas; do coletivismo, em que a felicidade não é individual, mas coletiva; da questão do dinheiro e das relações econômicas; do comércio; da relação entre tempo e espaço; do totalitarismo e do humanismo; ou mesmo das questões pedagógicas e educacionais.

Contudo, seus textos têm uma relação importante com o desapontamento do autor com a questão atual da depredação do meio ambiente e ele utiliza-se da literatura infanto-juvenil para conscientizar os jovens da importância de se preservar o ecossistema. Para tanto, foram às algumas dimensões utópicas que possibilitaram ao leitor a reflexão sobre diversas questões relevantes para o contexto atual, não apenas as ecológicas, mas também as relações sociais e econômicas.

Os dois livros são o resultado de toda uma série de discussões que aconteceram entre as décadas de 70,80 e 90 do século XX. Tratando de questões como a Camada de Ozônio, as favelas do Rio de Janeiro, a liberdade de escolha e de decisão, Wilson Rocha procurou através de dimensões utópicas, educar e conscientizar os brasileiros do futuro, para que a ecologia não seja mais uma utopia da espécie humana.

\section{DOCUMENTOS CONSULTADOS}

HOLANDA, Sérgio Buarque de. Visão do paraíso: os motivos edênicos no 
descobrimento e colonização do Brasil. São Paulo: Brasiliense, 2000.

KERN, Arno Alvarez. Utopias e missões jesuíticas. Porto Alegre: UFRGS, 1994.

MACCORMICK, John. Rumo ao paraíso: história do movimento ambientalista. Rio de Janeiro: Relume-Dumará, 1992.

RIBEIRO, Maurício Andrés. Ecologizar: Pensando o ambiente humano. Belo Horizonte: Rona Editora, 1998.

ROCHA, Wilson. O Filho das Estrelas. São Paulo: Moderna, 1989. (Coleção Veredas) ROCHA, Wilson. Os passageiros do futuro. São Paulo: Ática, 1987. (Série Vaga Lume) TROUSSON, Raymond. História de la literatura utópica: viajes a países inexistentes. Barcelona: Península, 1995.

1 Passageiros do Futuro é uma história que se inicia no ano 3000, em que quatro estudantes entre 12 e 14 anos da GLS (Grande Laboratório da Sapiência), uma escola para crianças superdotadas, decidem fazer uma viagem para o deserto de Zônia. B-Hor é um menino com uma capacidade de raciocínio e dedução muito avançada. Plick é uma pilha humana. Thera é a única garota do grupo, ela é uma mimetista, ou seja, pode se transformar em qualquer coisa. Delon é um garoto normal, mas de grande carisma, líder do grupo e aquele que tem a idéia de capturar um Planeta Anão e m Zônia. Quando conseguem a captura, os garotos decidem ampliar seu tamanho, que era menos que uma gota de orvalho, para poder pesquisa-lo, e conseguem fazer com que ele fique do tamanho de um crânio humano. Mas a atitude dos meninos é contra as regras da escola e da sociedade em que vivem, um ato há muito tempo não praticado, e por isso eles acabam sofrendo um julgamento feito pela Grande Bolha, o computador central que comanda a escola. Mas em meio ao julgamento, descobre - se que o planeta anão que foi ampliado tinha uma população que vivia nele, e que fugiu. Os adolescentes precisão encontrar os habitantes do Planeta Anão para que não sejam expulsos da escola, e para isso, quem os ajudará é Log, um robô antigo e atrapalhado mas muito fiel e Daam Paulo, um menino paranormal amigo do grupo. Na procura do povo anão desaparecido, Log se distrai e por vergonha de relatar seu erro passa a B-Hor dados errados. Esses dados errados e uma ajuda de Log acabam, por acaso, transportando Delon para 1987, onde conhece uma menina chamada Márcia que o ajudará a conhecer as belezas e as desigualdades do século XX. B-Hor, Thera e Plick, na tentativa de resgatar Delon são transportados para 1710, onde conhecem os horrores da guerra e as belezas da sociedade colonial. Com a ajuda de Sr. Delon Pai e da Grande Bolha, os meninos conseguem retornar ao seu tempo real, cheio de experiências e reflexões para partilhar com todos, além de uma descoberta que pode mudar a história da humanidade, que a muito não sabia mais o que era poder conviver com a fauna e a flora do planeta.

20 Filho das Estrela é um livro que conta a história de Marcelo, um menino de 10 anos que vai morar em um internato após a morte da mãe. Seu pai, o geólogo e arqueólogo Leo Façanha trabalha na procura de jazidas de metais e pedras preciosas e que, após muita insistência, decide levar Marcelo em uma missão exploradora pelo Planalto Central brasileiro. Instalado no "Acampamento do Dragão" no coração da mata, Leo decide partir sozinho de canoa pelo rio a procura de uma antiga obsessão, uma lendária Cidade Perdida. Marcelo, decidido a não se afastar do pai, entra clandestinamente em um helicóptero que leva suprimentos para o acampamento. Contudo, o helicóptero sofre um acidente e Marcelo é salvo por dois índios Cuna, de origem panamenha. Perto do abrigo dos índios, existia uma montanha temida por eles e que, após recuperado, Marcelo decide escalar. Lá descobre uma Cidade composta de nove pirâmides de metal alinhadas três a três formando um grande quadrilátero. Nelas viviam alienígenas de um planeta chamado Nebula, que usavam terráqueos de todo o globo para extrair minerais que precisavam e que já não existiam mais em seu planeta. Graças a uma marca de nascença, que os nebulanos chamaram de Shofa, Marcelo passa a ser considerado um Filho das Estrelas, um ser pertencente a uma casta de Salvadores do Universo que nascem de cinco em cinco milênios. Ibeorgum, o chefe da expedição na terra decide então adotar Marcelo, dando-lhe o nome de larula, passando a ele os Grandes Ensinamentos para que, na hora certa, ele pudesse seguir o seu destino de proteger a terra do próprio homem. 